\title{
Erratum
}

\section{The role of vacuole in plant cell death}

\author{
I Hara-Nishimura and N Hatsugai
}

Cell Death and Differentiation (2011) 18, 1950; doi:10.1038/cdd.2011.135

Correction to: Cell Death and Differentiation (2011) 18, 1298-1304; doi:10.1038/cdd.2011.70

Since the publication of this article, the authors noticed that a part of Figure 2 was missing. The correct figure is shown below.
The publisher would like to apologize for any inconvenience this may have caused.

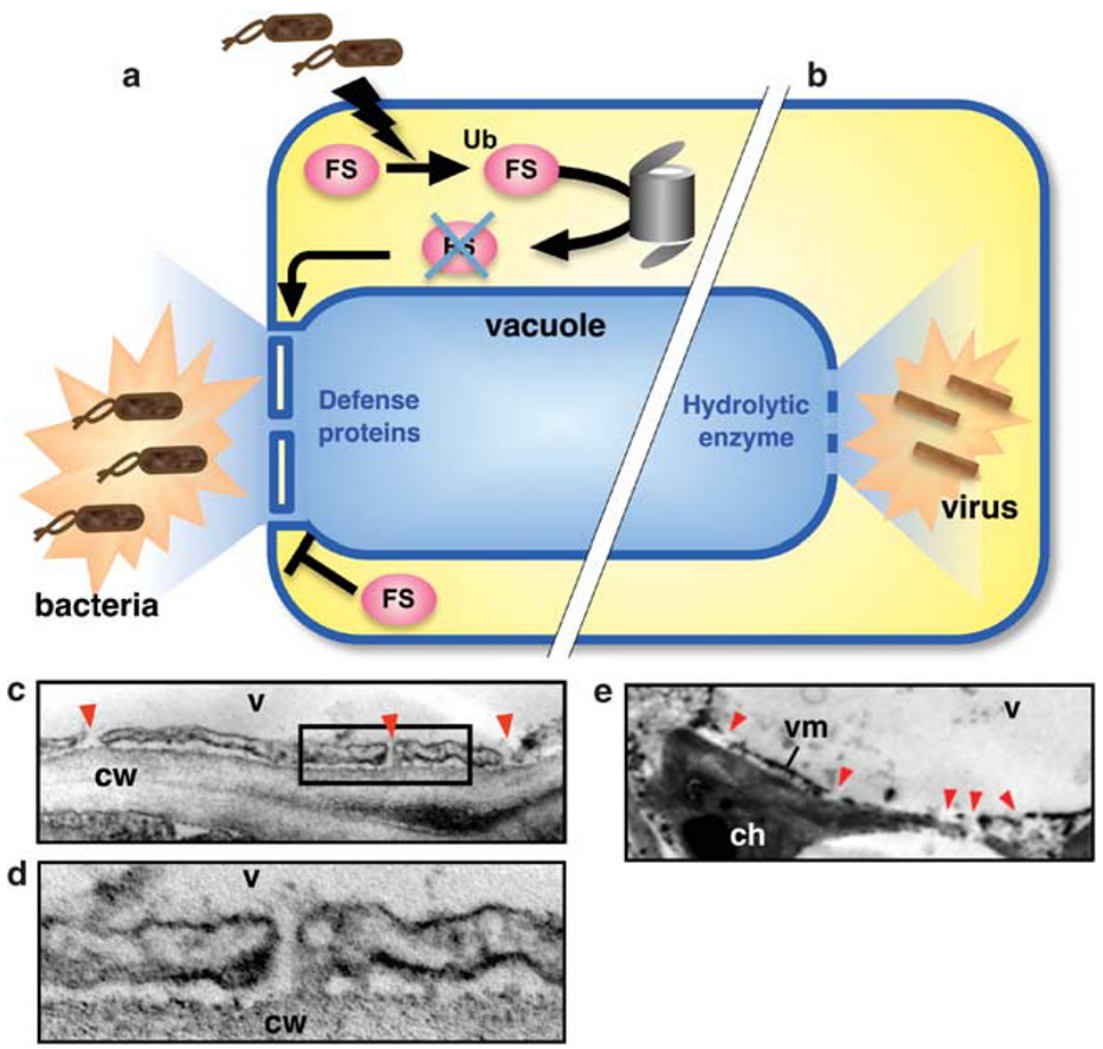

Figure 2 Two types of cell autonomous immune systems through vacuole-mediated cell death. Membrane fusion-mediated hypersensitive cell death against bacterial pathogens (a) and vacuolar collapse-mediated hypersensitive cell death against viral pathogens (b). Electron microscope pictures show bacterial infection-induced membrane fusion (c and $\mathbf{d}$ ) and viral infection-induced vacuolar membrane collapse (e). FS, fusion suppressor; Ub, ubiquitin 